\title{
Development of Spread Foundation Composed of Micropiles and Soilbags to Reduce Seismic Response of Structures
}

\author{
Tatsuya DOI \\ Soil Dynamics and Earthquake Engineering Laboratory, Center for Railway Earthquake Engineering Research \\ Seiji YAMADA \\ Architecture Laboratory, Structure Technology Division \\ Yoshitaka MURONO \\ Center for Railway Earthquake Engineering Research (Former)
}

\section{Ho CHO}

Department of Civil Engineering and Environmental, Nagoya Institute of Technology

The authors have developed a new type of foundation composed of micropiles and soilbags. The foundations are characterized by the laying of soilbags on pile heads and the construction of structures such as piers and rigid frame viaducts on the soilbags. The expected benefits are elimination of the need for pile-footing connections, a smaller diameter of piles, and a reduction in the response acceleration of structures. In this study, in order to clarify the characteristics of the seismic response of the developed structure, shaking table tests targeting piers on the supporting ground and on the developed structure were carried out. Moreover, reproduction analyses of shaking table tests were conducted using a $2 D$ FEM model, and the seismic response of the developed structure was successfully reproduced using the proposed analysis model.

Keywords: micropiles, soilbags, spread foundation, shaking table test

\section{Introduction}

It is well known that the response acceleration of a superstructure supported by a spread foundation is suppressed due to the rocking of the footing during an earthquake [1, 2, 3], which makes it possible to reduce the cross sectional area or amount of reinforcing bar in structures such as piers and rigid frame viaducts supporting the superstructure. On the other hand, it is difficult to construct spread foundations on soft ground because of a lack of bearing capacity. Therefore, it is common to ensure sufficient bearing capacity by adopting a pile foundation, for example. However, in a pile foundation, the horizontal force due to inertial force of the structures acts on the pile heads because the pile heads are generally joined rigidly to the footing. Consequently, the pile heads require large flexural strength, which often leads to excessively concentrated bar arrangements. Moreover, the cross-sectional area or amount of reinforcing bar of the structures often need to be increased because the reduction in response acceleration of the structures is not expected to be sufficient from a pile foundation.

In order to realize spread foundations on a soft ground and expect the reduction of response acceleration of a structure, separating the footing and the pile heads is effective. In this method, the reduction of the response acceleration of the structures due to lifting of the footing and subsequent period lengthening of the structures during an earthquake is expected, as well as in the spread foundation. Moreover, this foundation has a bearing capacity equivalent to that of a pile foundation, and it is possible to eliminate the need for pile-footing connections, and to decrease the diameter of the piles. For example, by model shaking table tests and corresponding numerical analyses,
Nishimura et al. [4] examined the seismic response of three types of pier, as follows:

(i) a spread foundation with ground improvement (a spread foundation pier on a soft ground partially replaced by column-like improved bodies)

(ii) a spread foundation pier on soft ground

(iii) a pile foundation pier

The test results confirmed that the spread foundation with ground improvement had both the effect of reducing the response acceleration of the pier and the effect of increasing bearing capacity. On the other hand, the columnlike improved bodies broke during the experiments, followed by residual settlement. This was a significant problem. Yamamoto et al. [5] confirmed by conducting insitu experiments with $1 / 10$ scale models that the stress of pile heads was able to be reduced by separating the piles from the footing.

The authors therefore developed the "spread foundations composed of micropiles and soilbags" (hereinafter referred to as the "developed structure") shown in Fig. 1

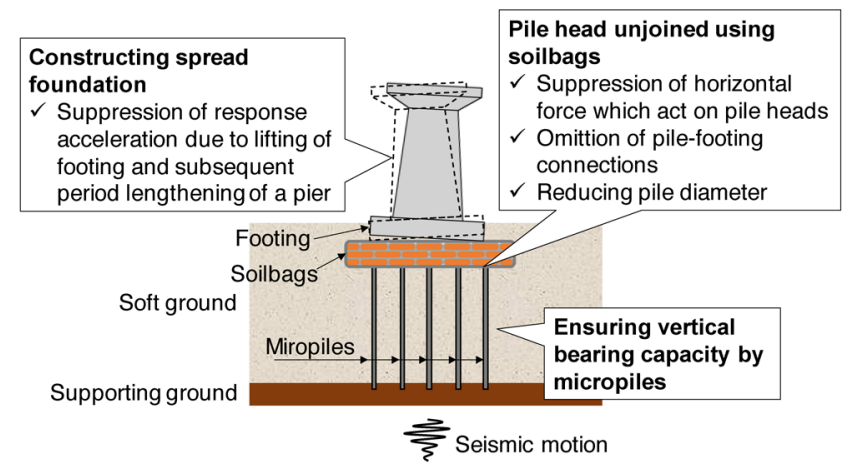

Fig. 1 Outline of developed structure 


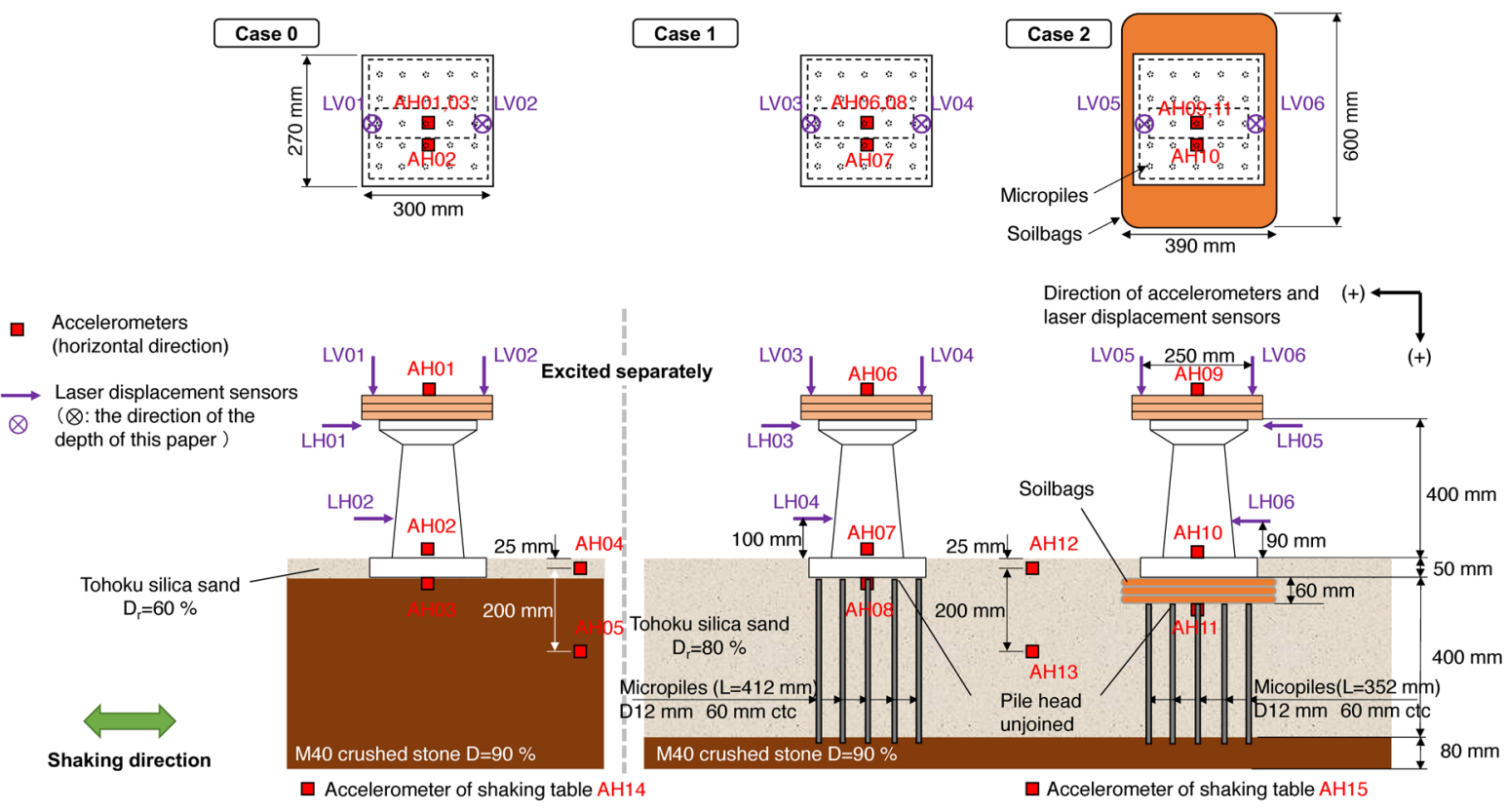

Fig. 2 Outline of the experiment cases and arrangement of the sensors

as a type of structure separating the pile heads from the footing mentioned above [6]. The developed structure is characterized by laying soilbags on the pile heads and constructing structures on the soilbags, and thus expecting the reduction of response acceleration of the structure. In addition, it is possible to omit the pile-footing connections, and to decrease the diameter of the piles since the piles are separated from the footing through the intermediary of the soilbags.

Moreover, the developed structure is characterized by laying soilbags between the pile heads and the footing. It is known that the compression strength and compression rigidity of soilbags are much greater than those of filling material only. That is because the circumference of the soilbags increases as the compression strain increases, therefore a tensile force is generated in the bag, and the horizontal force from the bag restrains the filling material, which consequently leads to an increase in the strength and the stiffness of the soilbags [7]. Therefore, soilbags are not expected to plasticize or be severely damaged, which prevents the concentration of stress on the piles located on the edge of the footing and on the soft ground beneath the soilbags. It should be noted that it is assumed that geotextile soilbags [8], consisting of geotextile and crushed stone, will be adopted for the developed structure instead of general soilbags often used in disaster recovery. That is because geotextile soilbags have a larger compression strength and rigidity, thus those are suited to lay beneath the footing of railway structure where large compressive force acts.

In this study, in order to clarify the seismic response characteristics of the developed structure, shaking table tests were conducted. The specimens included a spread foundation pier on the supporting ground with sufficient bearing capacity (hereinafter referred to as the "spread foundation pier"), a pier on the micropiles which is separated from the footing (hereinafter referred to as the "insulated pile foundation pier"), and the developed structure.

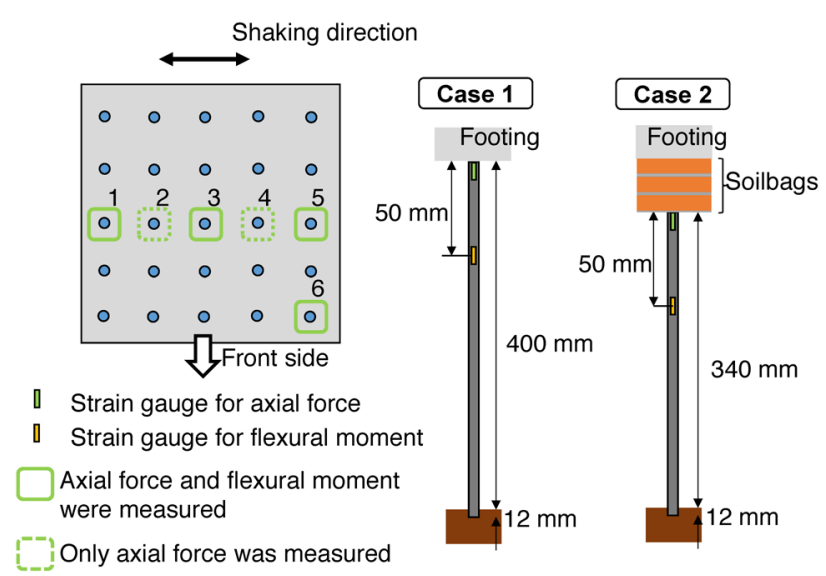

Fig. 3 Arrangement of the strain gauges installed in the micropiles

The response acceleration and sectional force of micropiles were examined in the light of test results. Moreover, in order to examine the mechanisms underlying the seismic response of the developed structure and the effect of reducing the sectional force of the micropiles due to laying soilbags, reproduction analyses of the shaking table tests were conducted.

\section{Clarification of the seismic response characteris- tics of the newly developed structure by shaking table tests}

\subsection{Outline of the shaking table tests}

In order to clarify the seismic response characteristics of the developed structure, shaking table tests targeting the scaled models were conducted. Figure 2 shows the outline of the experiment cases and the arrangement of the sensors. Figure 3 shows the arrangement of the strain 
gauges installed in the micropiles. The specimens included the spread foundation pier (Case 0), the insulated pile foundation pier (Case 1), and the developed structure (Case 2). The micropiles in Case 1 and Case 2 were separated from each footing. Case 1 and Case 2 were excited at the same time, and Case 0 was excited separately from Case 1 and Case 2. A middle-sized shaking table (excitable frequency from $1 \mathrm{~Hz}$ to $25 \mathrm{~Hz}$ ) and fixed soil tank (inner width $2.0 \mathrm{~m} \times$ inner depth $0.6 \mathrm{~m} \mathrm{x}$ inner height $1.5 \mathrm{~m}$ ) were used for the excitation. Mechanically stabilized crushed stone (M40, target degree of compaction $D_{\mathrm{c}}=90 \%$ ) was laid as a supporting ground layer. Then Tohoku silica sand (target relative density $D_{\mathrm{r}}=80 \%$ ) was laid as the soft ground layer. It should be noted that the relative density of Tohoku silica sand used in Case 0 was set to $60 \%$.

The model piers were $400 \mathrm{~mm}$ high, $300 \mathrm{~mm}$ wide at the footing and $270 \mathrm{~mm}$ deep at the footing, which is approximately $1 / 25$ of an actual railway pier. The soilbags were $390 \mathrm{~mm}$ wide, $600 \mathrm{~mm}$ deep, and $20 \mathrm{~mm}$ thick, which is larger than the size of the footing. Three soilbags were laid under the footing. In addition, the depth of the soilbags corresponds to the inner depth of the soil tank. High density polyethylene net (TNET-N3) was used for the bag material. The corners of the bags were stitched together. After the series of excitations, no damage to the soilbags was observed. No. 2 Kajima silica sand was used as the filling material of the soilbags and dry density was set to $1.6 \mathrm{~g} / \mathrm{cm}^{3}$. As micropiles, acrylic pipes with an outer diameter of 12 $\mathrm{mm}$ and an inner diameter of $6 \mathrm{~mm}$ (Young's modulus $E=$ $3.4 \times 10^{6} \mathrm{kN} / \mathrm{m}^{2}$ ) were used. Measurement items were the horizontal acceleration of the piers, horizontal and vertical displacement of the piers, and strain of the micropiles. The specimens were excited in the transverse direction using a Level-2 Spectrum I acceleration for a G3 soil condition (good soil condition) [9], whose acceleration was gradually increased from 100 gal to 900 gal. Then the test specimens were excited using a sine wave, whose acceleration was gradually increased to 100 gal, 300 gal, 500 gal, and 750 gal in this order. The time scale of the Level-2 Spectrum I acceleration waveform was compressed to $1 / 25^{0.5}=1 / 5$ of the original waveform to meet the law of similarity.

\subsection{Experimental results}

Figure 4 shows the relationship between the maximum acceleration of the shaking table (the maximum value of AH14 in Case 0, the maximum value of AH15 in Case 1 and Case 2) and the maximum response acceleration at the top of the piers (the maximum value of AH01, AH06, and AH09) when the Level-2 Spectrum I acceleration waves were excited. As shown from Fig. 4, the maximum values of response acceleration at the top of the piers reach plateaus with an amplitude in excess of around 400 gal both in Case 1 and Case 2. In addition, this tendency is the same with Case 0. It is known that the resisting moment of the supporting ground of the spread foundation has its limit, and the response acceleration of the piers peaks when the moment at the bottom of the footing reaches the limit value. This means that the spread foundations have almost the same bearing capacity when the response acceleration values of the piers plateau at the same acceleration values. Therefore, a reduction in the response acceleration and a
X Case 0 (Spresd foundation pier)

$\Delta$ Case 1 (Insulated pile foundation pier)

- Case 2 (Proposed structure)

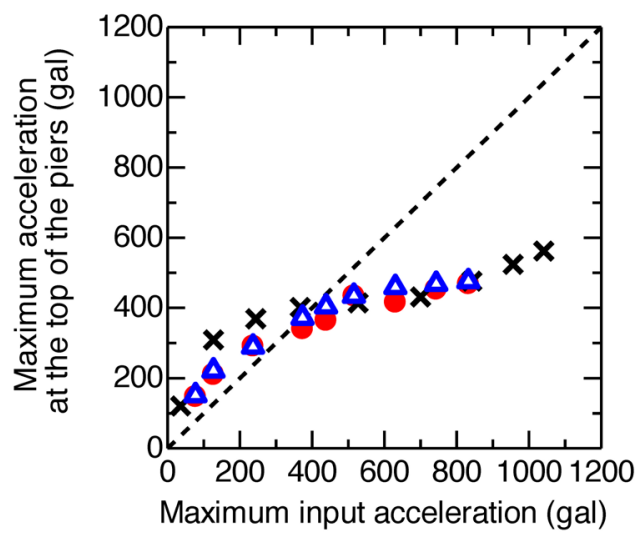

Fig. 4 Relationship between the maximum acceleration of the shaking table and the maximum response acceleration at the top of the piers

sufficient vertical bearing capacity are expected both in Case 1 and Case 2, which are the same as Case 0.

In the following, in order to confirm the effect of reducing sectional forces by laying soilbags in the developed structure, the sectional forces in Case 1 and Case 2 are examined. Figure 5 compares the time histories of the response displacement of the piers, axial force of the micropiles, and flexural moment of the micropiles when a sine wave with the maximum acceleration of 750 gal was excited. In Fig. 5, the values of the tensile axial force are taken as positive, and the values of the anticlockwise flexural moment are taken as positive. Figure 5 focuses on the time period from $5.6 \mathrm{~s}$ to $7.0 \mathrm{~s}$ (the $3 \mathrm{rd}$ to the 10 th wave out of all 10 waves) because the seismic response is sufficiently stable. In addition, in Fig. 5, the states before the vibration are defined as zero by reducing the average values of the data for $1.0 \mathrm{~s}$ before the vibration. The numbers of the legend in Fig. 5 correspond to the position of micropiles in Fig. 3. Figure 5 shows the common tendencies between Case 1 and Case 2 to be that the phases of the waveform of the axial force and the flexural moment have a reverse polarity between micropile 1 and micropile $5-6$, and that axial force and the flexural moment are large at the edge of the footing and small at the center of the footing. In addition, the axial force and the flexural moment of micropile 1 are larger than those of micropile 5. A possible reason is that the experimental results shown in Fig. 5 were affected by residual displacement or inclination due to the stage excitation conducted before the excitation of a sine wave with the maximum acceleration of 750 gal, although the exact reason cannot be detected from the experimental results.

As mentioned above, the experimental results in Case 1 and Case 2 have some common tendencies. On the other hand, the values of the axial force and the flexural moment are very different. As shown in Fig. 5 (a), a large axial force is generated locally in Case 1 which is a prominent tendency for micropile 6 . This tendency has been pointed out in shaking table tests conducted by Tazou et al [10]. In contrast, as shown in Fig. 5 (b), local and large axial forces are suppressed in Case 2. This is probably because the axial 

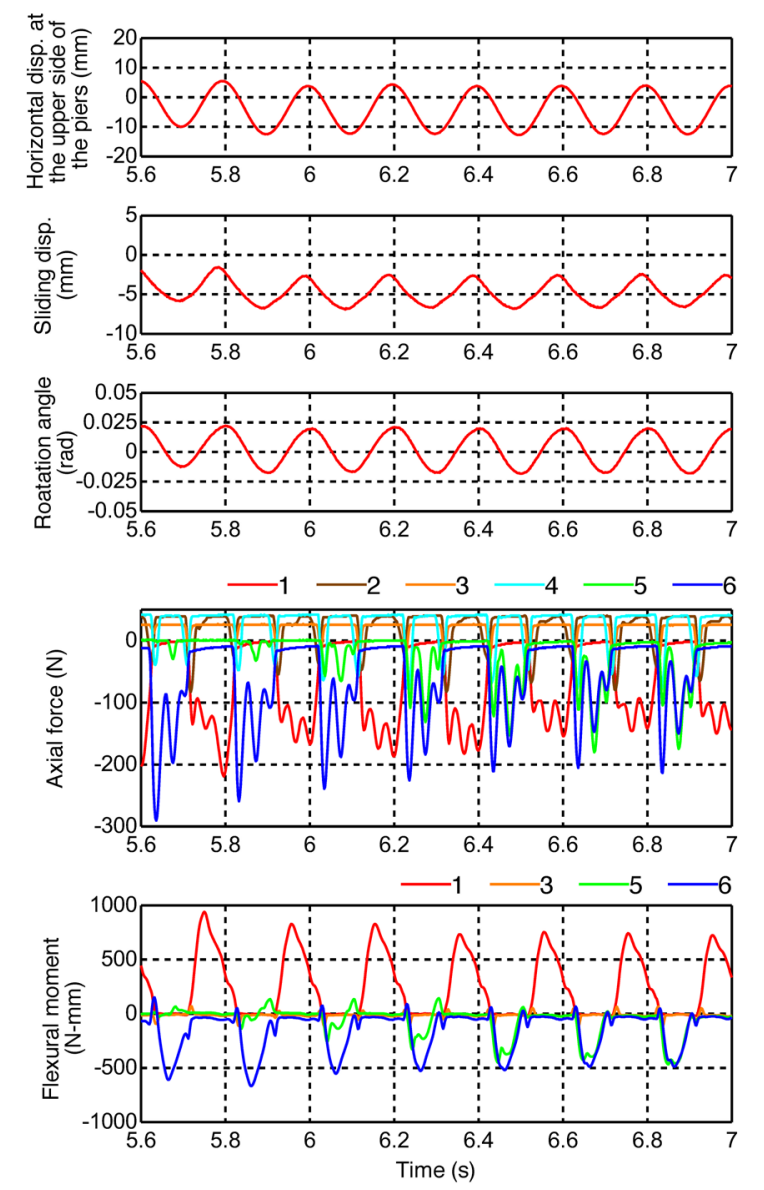

(a) Case 1 (insulated pile foundation pier)
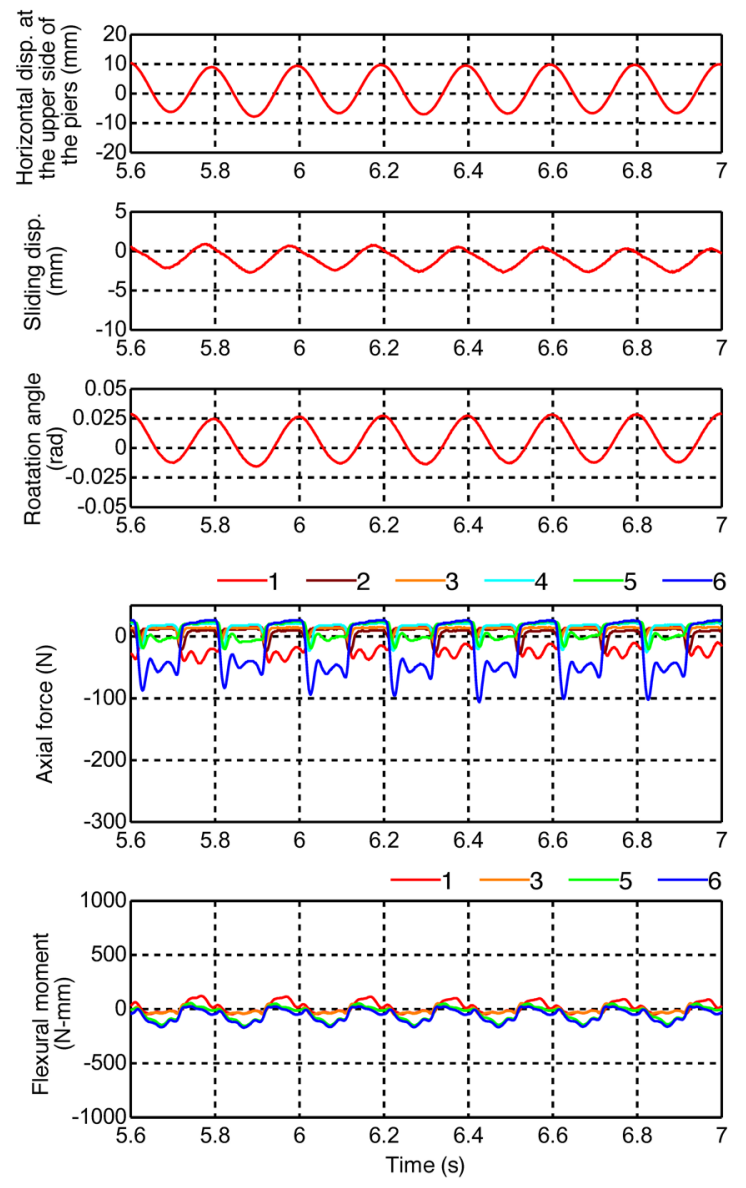

(b) Case 2 (developed structure)

Fig. 5 Comparisons of time histories of the response displacement of the piers, axial forces of the micropiles, and flexural moment of the micropiles (when a sine wave with the maximum acceleration of 750 gal was excited)

force on each micropile is normalized to some extent by the laying of the soilbags.

Moreover, Fig. 5 shows that the flexural moments of the micropiles in Case 2 are suppressed compared to those in Case 1. That is because the soilbags share a horizontal force and this force is dispersed to the ground and the micropiles under or in front of the soilbags, which is examined later comparing the results of Chapter 2 to those of the reproduction analyses in Chapter 3 . In addition, Fig. 5 (a) shows that in Case 1 the flexural moment of the micropile at the far side peaks first, then the sliding displacement peaks, followed in turn by the rotation displacement which peaks afterward. The same tendency was observed in Case 2.

These results indicate that large axial forces and flexural moments are generated locally in the micropile at the far side in the insulated pile foundation pier, while axial force and flexural moments are suppressed in the developed structure by laying the soilbags on the pile heads. In addition, it has already been confirmed apart that the same tendencies as those shown in Fig. 5 were observed when a Level-2 Spectrum I acceleration for a G3 soil condition was excited.

\section{Reproduction analyses of the shaking table tests}

\subsection{Outline of the reproduction analyses}

In order to examine the mechanisms underlying the seismic response of the developed structure and the effect of reducing the sectional force of micropiles by laying soilbags, reproduction analyses of the shaking table tests were conducted. The model of the reproduction analyses is shown in Fig. 6, and the parameters of the analyses are shown in Table 1 . The analyses were conducted with a dynamic nonlinear 2D FEM model. The target piers of the analyses were the insulated pile foundation pier (Case 1) and the developed structure (Case 2). The size of the ground was set to $2080 \mathrm{~mm}$ in width and $530 \mathrm{~mm}$ in height, which is the same size as the model ground of the shaking table tests. The bottom of the ground elements was constrained both in a horizontal and a vertical direction, and the side of the ground elements were constrained in vertical direction. The elements of the micropiles were modeled by elastic beam elements; the piers, the weights, the ground, and the soilbags were modeled by plane strain elements. The density of the piers and the weights were converted to the values per unit depth. The section area and the rigidity of micropiles were also converted to the 
Table 1 Parameters of analyses

\begin{tabular}{|c|c|c|c|c|c|}
\hline & $\begin{array}{c}\text { Wet density } \\
\rho_{\mathrm{t}}\left(\mathrm{t} / \mathrm{m}^{3}\right)\end{array}$ & $\begin{array}{c}\text { Initial shear modulus } \\
G_{0}\left(\mathrm{kN} / \mathrm{m}^{2}\right)\end{array}$ & Poisson's ratio $v$ & $\begin{array}{c}\text { Cohesion } \\
c\left(\mathrm{kN} / \mathrm{m}^{2}\right)\end{array}$ & $\begin{array}{c}\text { Internal friction angle } \\
\phi(\mathrm{deg})\end{array}$ \\
\hline Tohoku silica sand & 1.662 & $15411^{*}$ & 0.17 & 0.0 & 44.4 \\
Crushed stone & 1.940 & 35088 & 0.49 & - & - \\
Soilbag & 1.840 & 7047 & 0.49 & - & - \\
\hline
\end{tabular}

Table 2 Parameters of the GHE-S model of Tohoku silica sand layer

\begin{tabular}{|c|c|c|c|c|c|c|}
\hline$C_{1}(0)$ & $C_{2}(0)$ & $C_{1}(\infty)$ & $C_{2}(\infty)$ & $\alpha$ & $\beta$ & $\gamma_{0.5}$ \\
\hline 1.000 & 3.500 & 0.350 & 2.500 & 1.153 & 2.735 & $6.21 \times 10^{-5 *}$ \\
\hline
\end{tabular}

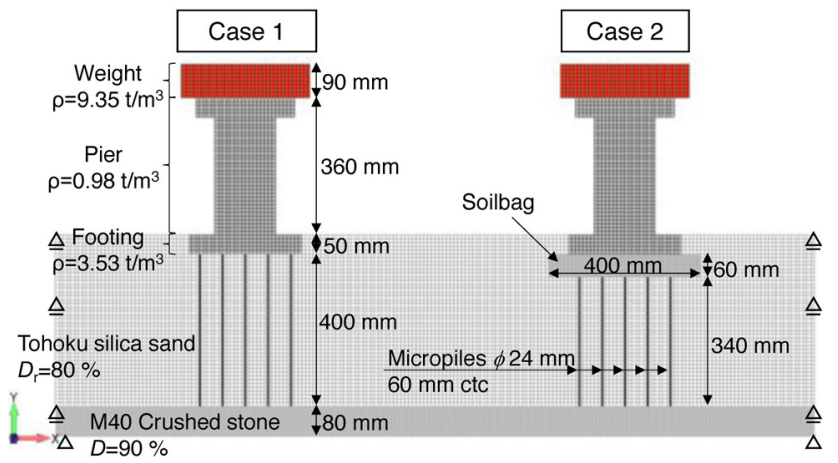

Fig. 6 Reproduction analyses model of the shaking table tests

values per unit depth. The materials of piers and the weights were modeled as elastic bodies with sufficiently large rigidity. The bottom of the footing and the ground and the micropiles in Case 1, and the bottom of the footing and the soilbag in Case 2 were joined by joint elements in order to model vertical thrust/separation and horizontal sliding. The horizontal tensile rigidity of springs between the side of the footing and the ground was set to almost zero in order to express the horizontal separation, while compression rigidity was set to a sufficiently large value. No vertical springs were set in between the side of the footing and the ground. The rigidities of springs in between the soilbag and the ground, the soilbag and the micropiles, the ground and the micropiles were set to sufficiently large values. The compression rigidity of the soilbag was set to the secant gradient of compression stress - the compression strain curve of the soilbags obtained from the previous compression test on the soilbag [11]. Nonlinearity of the Tohoku silica layer was expressed in the model using multispring and GHE-S model together. Parameters of the GHES model [12] of the Tohoku silica sand layer are shown in Table 2. The crushed stone layer was modeled using linear elastic elements. The input waves were Level-2 Spectrum I acceleration for a G3 soil condition and a sine wave of $5 \mathrm{~Hz}$ which were excited in the shaking table tests. It should be noted that repeated excitations were not considered since these reproduction analyses were aimed at qualitatively clarifying the mechanisms in seismic response of the developed structure. Numerical integration was conducted using the Newmark- $\beta$ method. The interval of integration was set to $1 / 500$ s. A damping matrix was set by element Rayleigh damping, where damping factors of the spring elements and the joint elements were set to zero and damping factors of the others were expressed by using the Rayleigh damping.

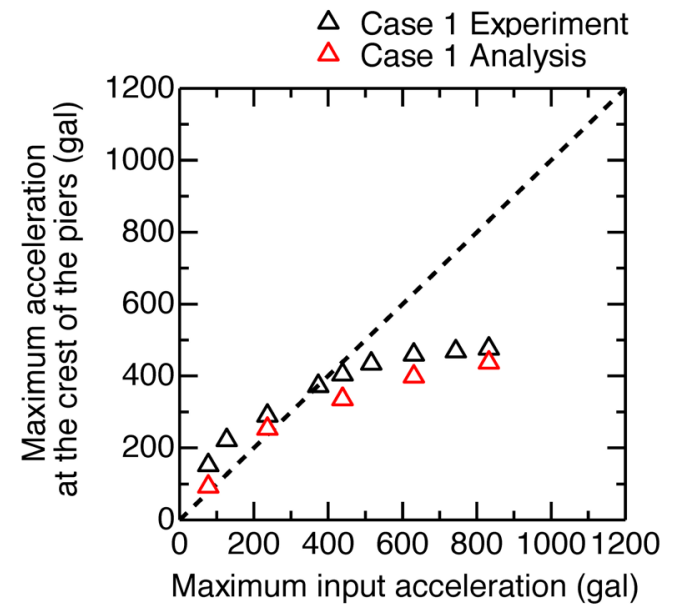

(a) Case 1 (insulated pile foundation pier)

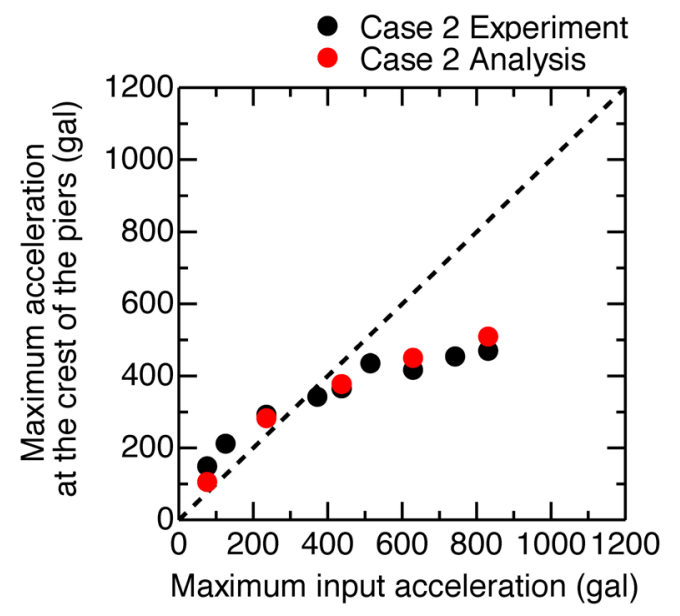

(b) Case 2 (developed structure)

Fig. 7 Comparison of relationships between maximum input acceleration and maximum response acceleration at the top of the piers

\subsection{Results of reproduction analyses}

A comparison of relationships between the maximum input acceleration (Level-2 Spectrum I acceleration) and the maximum response acceleration at the top of the piers is shown in Fig. 7. Figure 7 shows the maximum response acceleration values of the piers fall below the maximum input acceleration values as the input acceleration increases. 


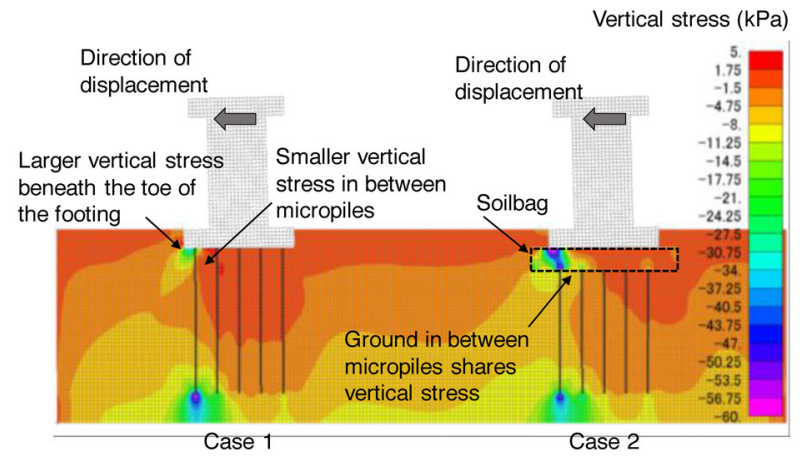

(a) Vertical stress

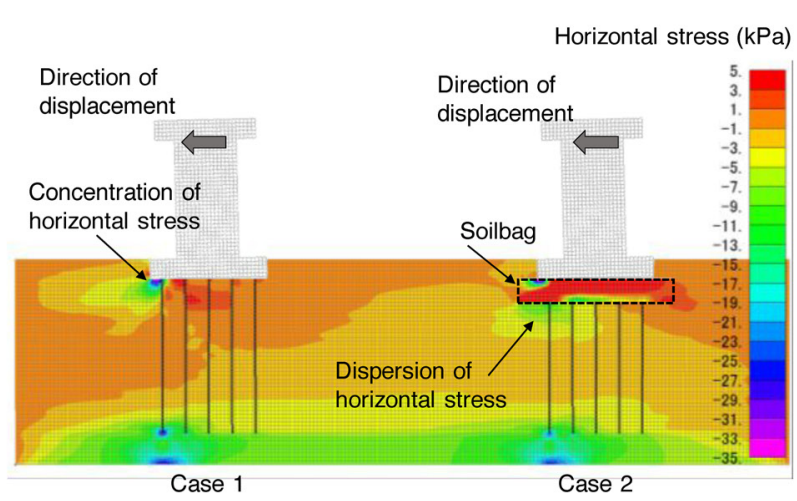

(b) Horizontal stress

Fig. 8 Stress contours of ground and soilbag at the time of maximum response displacement of the top of the pier in left direction

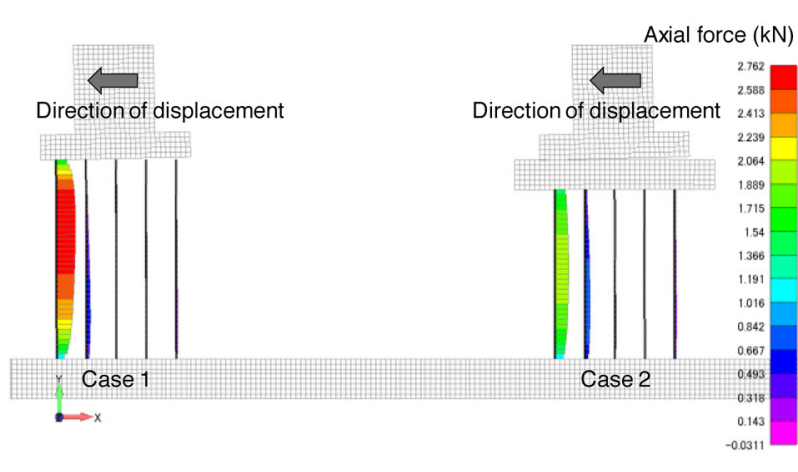

(a) Axial force

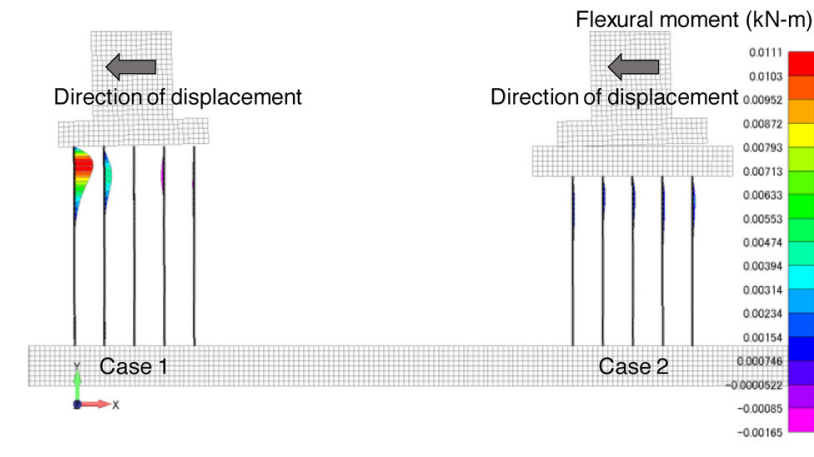

(b) Flexural moment

Fig. 9 Sectional force diagrams of micropiles at the time of maximum response displacement of the top of the pier in left direction

This tendency is consistent with the experimental results. From the above, suppression of the response acceleration of the piers observed in experiments can be reproduced properly by the developed analysis model.

In the following, in order to clarify the mechanism of the effect of reducing sectional force by laying soilbags in the developed structure, sectional forces of the analyses in Case 1 and Case 2 were examined. Figure 8 shows the stress distribution of the ground and the soilbag when a sine wave with target maximum acceleration of $750 \mathrm{gal}$ was excited, and Fig. 9 shows the sectional force diagrams of the micropiles. The time of interest in Figs. 8 and 9 is $5.156 \mathrm{~s}$, which is where the response displacement of the piers reaches its maximum value. In Fig. 8, tensile is taken as positive, and the range of the contour is set to the rounded values of the maximum and the minimum stress of Tohoku silica sand. In Fig. 9, compression is taken as positive in the axial force, the anticlockwise direction is taken as positive in the flexural moment. From Fig. 8 (a), it is found that the vertical stress of the ground concentrates beneath the toe of the footing and ground in between piles shares little vertical stress in Case 1. On the other hand, the vertical stress of the ground does not concentrate much beneath the toe of the footing and the ground in between piles shares the vertical stress to some extent in Case 2. Moreover, Fig. 9 (a) shows that the axial force of the micropile of the second row from the left side is larger in Case
2 than in Case 1. From the above, the axial force of the micropiles at both edges of the footing in Case 2 falls below that of Case 1 because the vertical load which acts on the upper side of the soilbags is dispersed through soilbags in the ground beneath the soilbags and the micropiles in the 2nd line from each far side of the footing, as well as the micropiles at the both outside edges of the footing.

Moreover, Fig. 8 (b) indicates that the horizontal force which acts on the upper side of soilbags is dispersed in the ground beneath the soilbag in Case 2, which consequently follows to normalization of the flexural moment of the micropiles as can be seen from Fig. 9 (b). From the above, the flexural moments of the micropiles at both edges of the footing in Case 2 fell below those in Case 1 because the horizontal load which acts on the upper side of the soilbags was dispersed in the ground beneath the micropiles except at the both edges of the footing, as well as the micropiles at the both edges of the footing.

\section{Conclusions}

In this study, in order to clarify the seismic response characteristics of the developed structure, shaking table tests were conducted. The specimens included a spread foundation pier on a supporting ground which had sufficient bearing capacity (the spread foundation pier), a pier 
on the micropiles which was separated from the footing (the insulated pile foundation), and a pier on the foundation which consisted of soilbags and micropiles (the developed structure). From the test results, response acceleration and sectional forces of micropiles were examined. Moreover, in order to examine the mechanism of the seismic response of the developed structure and the effect of reducing the sectional forces of micropiles due to laying the soilbags, reproduction analyses of the shaking table tests were conducted. The conclusions obtained in this study are as follows.

(1) In the shaking table tests, the maximum values of response acceleration at the top of the piers reach plateaus at the almost same acceleration value in all experimental cases: the spread foundation pier, the insulated pile foundation, and the developed structure. Therefore, the insulated pile foundation and the developed structure have almost the same bearing capacity as the spread foundation pier.

(2) In the shaking table tests, large axial forces and flexural moments were generated in the micropiles at both edges of the footing in the insulated pile foundation. On the other hand, the generation of large axial forces and flexural moments at both edges of the footing was suppressed in the developed structure.

(3) The reason why axial force and flexural moment of the micropiles in the developed structure are suppressed is because the vertical/horizontal load which acts on the upper side of the soilbags is dispersed in the ground beneath the soilbags and micropiles except at both edges of the footing, as well as the micropiles at both edges of the footing through the soilbags.

\section{References}

[1] Hayashi Y., "Damage reduction effect due to basement uplift of buildings," J. Struct. Constr. Eng., AIJ, No. 485, pp. 53-62, Jul., 1996 (in Japanese).

[2] Kawashima K. and Hosoiri K., "Effect of nonlinear rocking response of spread foundations on the hysteretic behaviour of bridges," Journal of JSCE, No. 703/ I-59, pp. 97-111, 2002. 4 (in Japanese).
[3] Haya H. and Nishimura A., "Proposition of design method of spread foundation considering large scale earthquake force," Journal of JSCE, No. 595/ VI-39, pp. 127-140, 1998. 6 (in Japanese).

[4] Nishimura T., Motoyama H., Izawa J., and Murono Y., "Experimental Study on Base Isolation Effect of Spread Foundation with Ground Improvement," Journal of JSCE, Vol. 68, No. 4, I_598-I_607, 2012 (in Japanese).

[5] Yamamoto M., Nakai S., Sekiguchi T., Fukutake K., and Taji Y., "Evaluation of earthquake behavior of the insulated pile foundation based on the site model experiment," Special issue: The 14th Japan Earthquake Engineering Symposium, pp. 343-353, 2015 (in Japanese).

[6] Doi T., Naoyuki O., Yamada S., Murono Y., and Cho H., "Experimental study on seismic response of foundation composed of micropiles and soilbags," Journal of Structural Engineering, A, pp. 164-177, 2019 (in Japanese).

[7] Matsuoka H., Liu S., Hasebe T., and Shimao R., "Deformation-strength properties and design methods of soilbag assembly," Journal of JSCE, No. 764/ III-67, pp. 169-181, 2004. 6 (in Japanese).

[8] Nonaka T., Kojima K., Yonezawa T., Sato T., Morino T., and Aoki H., "Property of Gabion Laid between the Head Part of Improvement Pile and Concrete Slab for Pile Slab Track," Geosynthetics Engineering Journal, No. 27, 93-100, 2012 (in Japanese).

[9] Railway Technical Research Institute, Design Standards for Railway Structures and Commentary (Seismic Design), Maruzen, Tokyo, Japan, 2012.

[10]Tazou T., Shimizu K., Hirose T., "Seismic destruction experiment of piles," Technical research report of Shimizu Construction Co., Ltd., No. 50, 1989 (in Japanese).

[11] Doi T., Murono Y., and Cho H., "Model Test and Corresponding Simulation on Compressive Characteristics of Soilbags," 5th World Congress on Civil, Structural, and Environmental Engineering, Lisbon, Portugal, 2020.

[12] Nogami Y., Murono Y., “Nonlinear Hysteresis Model Taking into Account S-Shape Hysteresis Loop and Its Standard Parameters," The 30th JSCE Earthquake Engineering Symposium, 2010 (in Japanese).

\section{Authors}

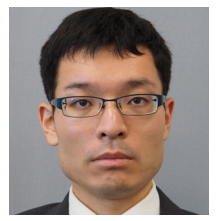

Tatsuya DOI

Assistant Senior Researcher, Soil Dynamics and Earthquake Engineering Laboratory, Center for Railway Earthquake Engineering Research

Research Areas: Earthquake Engineering

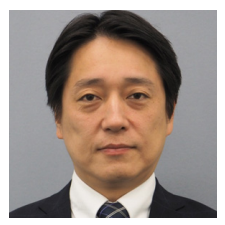

Seiji YAMADA, Dr. Eng.

Senior Chief Researcher, Head of Architecture Laboratory, Structure Technology Division Research Areas: Earthquake Engineering

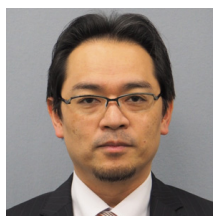

Yoshitaka MURONO, Dr. Eng.

Director, Center for Railway Earthquake Engineering Research (Former) Research Areas: Earthquake Engineering

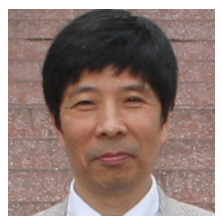

Ho $\mathrm{CHO}$, Dr. Eng.

Professor, Department of Civil Engineering and Environmental, Nagoya Institute of Technology Research Areas: Geotechnical Engineering 